\title{
Commentary on 'The effect of depot medroxyprogesterone acetate on postnatal depression: a randomised clinical trial'
}

\section{Jonathan Schaffir}

Associate Professor, Department of Obstetrics and Gynecology, The Ohio State University, Columbus, $\mathrm{OH}$, USA

\section{Correspondence to} Dr Jonathan Schaffir, Department of Obstetrics and Gynecology, The Ohio State University, Wexner Medical Center, 493C McCampbell Hall, 1581 Dodd Drive, Columbus, OH 43210, USA; jonathan. schaffir@osumc.edu

Accepted 5 May 2016 Published Online First 25 May 2016

\section{CLinked}

- http://dx.doi.org/10.1136/ jfprhc-2015-101334

\section{CrossMark}

To cite: Schaffir J. J Fam Plann Reprod Health Care 2016;42:177-178.
Providing effective contraception is a key component of postpartum care. Making sure that a woman does not get pregnant again before she is ready is important for both maternal and infant health. Preventing a short interpregnancy interval ensures adequate time to bond and care for the infant, allows adequate time for maternal recovery, and prevents complications with future pregnancy, such as preterm birth and low birth weight. ${ }^{1}$

Depot medroxyprogesterone acetate (DMPA) has several characteristics that make it ideal for this purpose. It is highly effective, reasonably inexpensive, does not require special training for administration, and does not rely on patient compliance for its efficacy. Furthermore, it is easily administered in a postpartum setting, and it is compatible with breastfeeding. ${ }^{2}$

The convenience and effectiveness of DMPA must be balanced with its safety and side effects. In their J Fam Plann Reprod Health Care paper, Singata-Madliki et al. ${ }^{3}$ provide evidence that immediate administration of DMPA to postpartum mothers may put them at greater risk of depressive symptoms than using other long-acting forms of birth control. In comparing women who receive DMPA immediately postpartum with those who receive an intrauterine device, they show that the women on DMPA have significantly higher scores on the Beck Depression Inventory at 3 months, and significantly more of them achieve scores that would suggest a depression diagnosis. If indeed there is a higher risk of postpartum depression, this may itself have adverse effects on both maternal cognition and emotionality and infant cognition and behaviour. ${ }^{4}$

The suggestion that long-acting progestogens may have some adverse effect on mood has biological plausibility. Receptors for gonadal steroids have been identified in key areas of the brain that are involved with mood, and animal studies have demonstrated behavioural effects when exogenous progestogens are administered. ${ }^{5}$

Given these findings, the clinician providing postpartum care may well wonder whether the risks outweigh the benefits of this highly effective contraceptive method. The evidence provided in this paper is not sufficient to abandon postpartum DMPA quite yet. Although the difference in depression screening scores was significant, there was no clinical diagnosis of depression made. Furthermore, the absolute difference in scores, while statistically significant, was small, suggesting that the effect is probably not clinically relevant for the large majority of users.

Nevertheless, these results do provoke an element of caution. A subset of postpartum women may be particularly susceptible to the mood effects of exogenous hormones. Further research is needed to determine if these women may be identified by risk factors such as a previous history of depression, or a history of psychological side effects on previous exposure to hormonal contraception. Until this knowledge is available, it would be prudent for health care providers to be aware of, and screen for, potential mood changes in their patients who use DMPA postpartum.

Competing interests None declared.

Provenance and peer review Commissioned; internally peer reviewed.

\section{REFERENCES}

1 Shachar BZ, Lyell DJ. Interpregnancy interval and obstetrical complications. Obstet Gynecol Surv 2012;67:584-594.

2 Jurow R, Shoupe D. Long-acting progestin injectables. In: Shoupe D, Kjos SL (eds), The 
Handbook of Contraception: A Guide for Practical Management. Totowa, NJ: Humana Press, 2006:101.

3 Singata-Madliki M, Hofmeyr GJ, Lawrie TA. The effect of depot medroxyprogesterone acetate on postnatal depression: a randomised controlled trial. J Fam Plann Reprod Health Care 2016;42:171-176.
4 O'Hara MW, McCabe JE. Postpartum depression: current status and future directions. Annu Rev Clin Psychol 2013;9: 379-407.

5 Genazzani AR, Stomati M, Morittu A, et al. Progesterone, progestogens and the central nervous system. Hum Reprod 2000;15(Suppl. 1):14-27.

\section{VACANCY - SOCIAL MEDIA EDITOR, JFPRHC}

Journal of Family Planning and Reproductive Health Care (JFPRHC), published by BMJ on behalf of the Faculty of Sexual and Reproductive Health Care in the UK, has an exciting vacancy for an enthusiastic Social Media Editor to drive the journal's web presence worldwide.

JFPRHC is a peer reviewed journal that aims to improve reproductive and sexual health nationally and internationally, and publishes high quality research and information relevant to clinical care, service delivery, training and education in the field of contraception and reproductive/sexual health. More information can be found at jfprhc.bmj.com.

JFPRHC already has a strong readership and offers online features such as a blog, podcasts, Facebook and Twitter. The journal is searching for someone to support the editorial team in improving the journal's visibility and reach via these and other social media, by promoting the journal's content as well as helping its core readership to stay up to date with news and developments in the field.

Candidates should be educated to postgraduate level with knowledge of the journal's subject area. Some experience of science communication and/or digital content management systems such as Twitter, Facebook and WordPress would be preferred, but the main criteria for the successful applicant will be enthusiasm for the subject area, creativity, and an interest in using new technologies to disseminate scientific research. The role would be ideally suited to a junior researcher or practising clinician, and they may be based anywhere in the world.

The Social Media Editor will report directly to the journal's Editor-in-Chief, and will be expected to participate occasionally in the journal's regular editorial meetings (either in person or remotely by telephone or videoconference). This is an unpaid position, but training and support will be provided by BMJ's digital communications team.

To apply, please send your CV and covering letter to Lindsey Fountain, Associate Publisher at BMJ, at Ifountain@bmi.com.

Deadline: $30^{\text {th }}$ July 2016 